\title{
Correspondence
}

\section{L-tryptophan and EMS}

\section{DeAr SIRS}

We are grateful to Dr Cowen for providing his expert opinion on L-tryptophan and the eosinophiliamyalgia syndrome (Psychiatric Bulletin, December $1990,14,738-739)$. We agree with his contention that L-tryptophan is not an essential first-line treatment in the management of depression.

The recent guidelines of the European Community Committee on Proprietary Medicinal Products for the investigation of antidepressant drugs propose that efficacy is established not only in the treatment of acute episodes of illness, but also in maintenance treatment following resolution of the acute episode, and in prophylaxis to reduce the risk of new episodes. The evidence for efficacy of L-tryptophan in shortterm treatment is somewhat limited - a thorough review (d'Elia et al, 1978) suggests that L-tryptophan is probably inferior to 'standard' antidepressants such as imipramine, and is not significantly different to placebo. Furthermore, there is no convincing evidence for the efficacy of L-tryptophan in long-term treatment, and it is therefore difficult to recommend such treatment when evidence of long-term benefit is scarce.

Although L-tryptophan may occasionally be found to be useful in combination treatment of chronically-ill or treatment resistant depressed patients, caution must be exercised when interpreting reported results. It is regrettable that there are no generally accepted criteria for 'resistant' depression. Perhaps the most acceptable definition of 'chronicity' is that of Cassano et al (1983), i.e. symptomatic non-recovery for a period of two or more years. However, utilisation of even this simple definition results in the description of a diverse and heterogenous patient group (Scott, 1988). The studies which Dr Cowen praises are flawed for a number of reasons, including insufficiently stringent diagnostic criteria (Coppen et al, 1963), small numbers, and 'open' treatment regimes (Barker et al, 1990). Similarly, tryptophan discontinuation studies of an open nature may encourage the generation of hypotheses, but do not permit an unbiased appraisal of the merits of treatment.

Eosinophilia-myalgia syndrome is a serious illness, which carries an appreciable mortality. Although the association of EMS with L-tryptophan may ultimately prove to be either indirect or tenuous, its advent does at least allow some time for reflection on the limited evidence for efficacy of L-tryptophan in the treatment of depression.

David BaLdWIN

PAUL COSFORD

St Mary's Hospital

Praed Street, London W2 INY

\section{References}

Barker, W. A., Scott, J. \& Ecclestone, D. (1990) The Newcastle chronic depression study: results of a treatment regime. International Clinical Psychopharmacology, 2, 261-272.

Cassano, G. B., Maggini, C. \& Akiskal, H. (1983) Shortterm, subchronic and chronic sequelae of affective disorders. Psychiatric Clinics of North America, 6, 55-68.

Coppen, A., Shaw, D. \& Farrell, J. (1963) Potentiation of the antidepressive effect of a monoamine oxidase inhibitor. Lancet, i, 79-80.

d'Elia, G., Hansom, L. \& RaOtma, H. (1978) L-tryptophan and 5-hydroxytryptophan in the treatment of depression. Acta Psychiatrica Scandinavica, 57, 239-252.

ScotT, J. (1988) Chronic depression. British Journal of Psychiatry, 153, 287-297.

\section{Research by junior doctors}

\section{DeAr Sirs}

It was refreshing to read Drs Guthrie \& Black's view of research from the standpoint of the junior psychiatrist (Psychiatric Bulletin, December 1990, 14, 719-720). I believe, however, that they have tactfully understated the difficulties. These are:

(a) 'good' research takes too long and is too time-consuming to be incorporated in the training programme

(b) a target of publication leads to an almost impossible standard of methodology

(c) an approach to most academics leads to a catalogue of difficulties which stultifies enthusiasm.

The result of these difficulties is that research, with few exceptions, is postponed to the senior registrar phase of training. I would propose that SHOs and registrars should be allocated, yes allocated, small studies or experiments which would take no more than nine months to complete while pursuing a standard training course. If such projects produced encouraging results they could be expanded into 'good' research at the senior registrar stage. Meanwhile, they would introduce the junior doctor to the excitement of the unknown and once the original hurdle of doing a research project is surmounted, 
then, like suicide, the second attempt becomes much more likely.

The College could encourage this activity by publishing an Annual Bumper Book of Coarse Psychiatric Research which would contain selected synopses of these works. What a joy to read short accounts of all ideas pursued by our bright young doctors!

The only good research is coarse research. 'Good' research is the mopping up of the successful ideas generated by coarse research. The encouragement of original thinking is a prime educational responsibility of our College.

Warlingham Park Hospital

C. McDonald

Warlingham, Surrey CR3 9YR

\section{Support and stay}

DeAR SIRS

The interesting article by Whitby and his colleagues 'Support and stay: an innovative community service for the elderly confused' (Psychiatric Bulletin, December 1990, 14, 708-710) illustrates marked differences in the balance between health and social services provision for the demented elderly across the country. In our own health district the sort of activities described by Whitby are entirely the province of social services: now the subject of a pilot project involving budget-holding case managers who can arrange an even more flexible package of care than that provided by the "Sas" service reported by Whitby. My main question is this: in what way does a psychogeriatric service differ from a social service? There is nothing in Whitby's article that suggests that the "Sas" service should not be available to all clients with a dementia, rather than only those referred to a specialist service.

United Medical and Dental School

A. J. D. Macdonald

Hither Green Hospital

London SE13 6RU

\section{Personal experience with clozapine}

DeAR SIRS

Clozapine is a dibenzodiazepine derivative. In 1975, granulocytopaenia developed in 16 patients taking clozapine in Finland. Subsequently 13 of these developed agranulocytosis and eight died from secondary infection (Griffith \& Saameli, 1975). A multi-centre trial in the USA involving 319 patients (Kane $e t$ al, 1988) and a study in Germany involving 387 patients (Naber et al, 1989) produced only one death; a causal relationship between clozapine and the fatality could not be excluded but was not probable. The present risk rate of white cell problems has been summarised at $1-2 \%$ which should be taken with a comparable risk of $0.01-0.1 \%$ of agranulocytosis with phenothiazines.

The current prescribing regulations in the UK demand weekly white cell counts for 18 weeks, which is the high risk period, and fortnightly white cell counts thereafter. Worldwide experience suggests that if this is strictly adhered to, and tablets are supplied only on receipt of normal white cell results, then all cases of agranulocytopaenia will recover solely on rapid cessation of the drug.

Clozapine was introduced in the spring of 1990 to the UK and marketed to consultant psychiatrists in NHS practice. Currently only $10 \%$ have used it and most have given it to only one or two patients. There are only about 500 patients who have experienced the drug in this country. Because of the above diffculties, Sandoz UK have suggested that the drug is used for schizophrenic patients who are resistant to conventional antipsychotic therapy or who do not tolerate these drugs.

I have prescribed clozapine for a total of 13 patients for a maximum of eight months and all but one are still on the drug. In two cases I had to discontinue the drug due to lack of response and in one case the patient refused to take the drug due to his paranoid state. All three of these cases were recommenced with some improvement. The one case that was not recommenced suffered a severe extra-pyramidal reaction as he had done with conventional drugs but recovered with anti-parkinson drugs and discontinuation of the clozapine. There were no cases of agranulocytopaenia that were serious enough to cause a 'red alert' and stop the drug but several cases triggered an 'amber alert' occasionally due to a damaged sample.

There were eight males and five females, all caucasian, and the age range was from $20-52$. Seven out of the eight males had spent time on an interim secure unit. The dose range of clozapine was from $300-900 \cdot \mathrm{mg}$ daily with some on a single nightly dose and others on split dosage. All the patients had been on oral and depot phenothiazines and most had been on at least three different depots in doses up to $1000 \mathrm{mg}$ fluphenazine decanoate weekly or equivalent. The duration of illness ranged from two to 17 years and all but three had been admitted to hospital before the start of the clozapine.

The side effects seen most commonly were hypersalivation and morning drowsiness, but one case suffered tachycardia and three cases had a total of five grand mal fits. Two of these were being withdrawn simultaneously from benzodiazepines. Most of the patients were left on anti-parkinson medication and two were left on lithium carbonate but other anti-psychotic drugs were used in only three patients. 